\title{
Anterior interosseous nerve syndrome: retrospective analysis of 14 patients
}

\author{
Dietmar Ulrich · A. Piatkowski • Norbert Pallua
}

Received: 18 April 2011 / Published online: 25 May 2011

(C) The Author(s) 2011. This article is published with open access at Springerlink.com

\begin{abstract}
Introduction The anterior interosseous nerve (AIN) is a only motor nerve innervating the deep muscles of the forearm. Its compression is rare. We present a retrospective analysis of 14 patients with an AIN syndrome with a variety of clinical manifestations who underwent operative and conservative treatment.

Patients and methods Fourteen patients (six female, eight male, mean age $48 \pm 9$ years) were included. In six patients, the right limb was affected, and in eight patients the left limb. Conservative treatment was started for every patient. If no signs of recovery appeared within 3 months, operative exploration was performed. Final assessment was performed between 2 and 9 years after the onset of paralysis (mean duration of follow-up $46 \pm 11$ months). Patients were examined clinically for return of power, range of motion, pinch and grip strengths. Also the disability of the arm, shoulder, and hand (DASH) score was calculated.

Results Seven of our 14 patients had incomplete AIN palsy with isolated total loss of function of flexor pollicis longus (FPL), five of FPL and flexor digitorum profundus (FDP)1 simultaneously, and two of FDP1. Weakness of FDP2 could be seen in four patients. Pronator teres was paralysed in two patients. Pain in the forearm was present in nine patients. Four patients had predisposing factors.
\end{abstract}

D. Ulrich $(\square)$

Department of Plastic and Reconstructive Surgery,

Erasmus University Hospital, 2040, 3000 CA Rotterdam,

The Netherlands

e-mail: d.ulrich@erasmusmc.nl

A. Piatkowski · N. Pallua

Department of Plastic and Reconstructive Surgery,

Aachen University of Technology, Aachen, Germany
Eight patients treated conservatively exhibited spontaneous recovery from their paralysis during 3-12 months after the onset. In six patients, the AIN was explored 12 weeks after the initial symptoms and released from compressing structures. Thirteen patients showed good limb function. In one patient with poor result a tendon transfer was necessary. The DASH score of patients treated conservatively and operatively presented no significant difference.

Conclusion AIN syndrome can have different clinical manifestations. If no signs of spontaneous recovery appear within 12 weeks, operative treatment should be performed.

Keywords Anterior interosseous nerve syndrome - Upper extremity - Decompression - Conservative treatment

\section{Introduction}

Nerve compression syndromes are a common cause of pain, sensory disturbance, and motor weakness in both the upper and the lower extremities [14]. The incidence of palsy in the anterior interosseous nerve (AIN) is low and accounts for less than $1 \%$ off all compression syndromes in the upper limb [1, 5, 25, 38]. The lesion is now being diagnosed more commonly due to an increased awareness of the condition by orthopaedic and plastic surgeons.

The AIN is purely a motor nerve. The detailed anatomy and its normal variation have been discussed by Sunderland [36, 37], Mangini [20], and Spinner [33]. It arises 5-8 cm distal to the lateral epicondyle, although the fibres destined to form it may be isolated as far proximally as the level of the brachial plexus [36]. The nerve passes through or under the pronator teres and travels along the anterior aspect of the interosseous membrane to the wrist. It innervates the pronator quadratus, the flexor digitorum 
profundus (FDP) to the index and long fingers, and the flexor pollicis longus (FPL). Paresis or paralysis of the AIN manifests clinically as weakness in the flexion of the interphalangeal joint of the thumb or the distal interphalangeal joints of the index and long fingers. Anatomically, a variety of local compression points are known to predispose the patients for the development of spontaneous AIN syndrome [11,23]. Trauma is another common aetiology [2, $3,22,35]$. Iatrogenic injury to the nerve may result from surgery [16], dressings [4], slings [26], and venepuncture [28]. AIN dysfunction has also been reported after elbow arthroscopy [15] and shoulder arthroscopy [31].

Lesions of the AIN can result in a variety of clinical manifestations, depending on the location and the degree of axonal damage. Clinical presentation with an isolated palsy of the FPL muscle is difficult to distinguish from a closed tendon rupture, especially after trauma. Due to the relative rarity of this syndrome, few controlled studies exist to determine the most effective treatment techniques.

We present a retrospective analysis of 14 patients with an AIN syndrome with a variety of clinical manifestations who underwent conservative and operative treatment.

\section{Patients and methods}

We obtained institutional review board approval before performing this retrospective study and conducted a chart review to identify the patients who underwent either conservative or operative treatment of AIN palsy. Fourteen patients treated between January 2002 and 2009 were reviewed. Six patients were female, eight male. Mean age was $48 \pm 9$ years. In six patients, the right limb was affected, and in eight patients the left. Two of the patients were secondary referrals and had begun to show signs of recovery. The diagnosis was confirmed by electromyography(EMG). Conservative treatment had been started in each patient. If no signs of recovery appeared within 3 months, operative exploration was performed.

Final assessment was performed between 2 and 9 years after the onset of paralysis (mean duration of follow-up $46 \pm 11$ months). Patients were examined clinically for the return of power, range of motion, and pinch and grip strengths. The result was graded according to a study from Sood and Burke [32] as good if the grip and pinch strengths and the range of motion in the joints of the affected digits were within $20 \%$ of the unaffected side, fair if the discrepancy was greater than $20 \%$, but the patient had regained useful function and poor if the lack of power and movement was a hindrance in normal activities. A postoperative disability of the arm, shoulder, and hand (DASH) score was also calculated [39]. No preoperative DASH score was available in this review. The DASH outcome measure is a thirty-item, self-reported questionnaire designed to measure the physical function and symptoms in people with musculoskeletal disorders of the upper extremity. The DASH scoring system is measured on a 100-point scale, where 0 represents no disability and 100 represents total disability. Data from the completed questionnaires were analysed using independent $t$ tests (SPSS software, version 17.0; SPSS, Inc., Chicago, IL). Significance was set at $p<0.05$.

\section{Results}

We found no significant differences in gender or in the side affected. Seven of our 14 patients had incomplete AIN palsy with isolated total loss of function of FPL. The FPL and FDP1 were paralysed simultaneously in five patients and the FDP1 alone in two patients. None of our patients had paralysis of FDP2. Weakness of FDP2 could be seen in four patients. Pronator teres was paralysed in two patients. Pain in the forearm was present in nine patients.

Four of our patients had predisposing factors such as influenza-like illness $(n=3)$ and venipuncture $(n=1)$. None of the patients had a history of trauma. In all the patients, treatment started conservatively. Eight patients treated conservatively exhibited spontaneous recovery from their paralysis during 3-12 months after onset. In all of these patients, signs of recovery started within 3 months after the initial symptoms. In six patients, the AIN was explored 3 months after the beginning of the symptoms. In all patients treated operatively, compressing structures were found intraoperatively (Fig. 1). The time of full recovery in these patients ranged from 3 to 11 months.

Thirteen of our patients showed good limb function, only one patient had a poor result with persistent paralysis after operation. In this patient, a tendon transfer was necessary.

There was no significant difference in $(29 \pm 4$ vs. $31 \pm 3$ points) the DASH score of patients treated conservatively and operatively presented at the time of the final follow-up.

\section{Discussion}

Duchenne de Boulogne [8] in 1872 reported an isolated palsy of the FPL in 1872. This was the first description of an AIN neuropathy. In 1952, Kiloh and Nevin [17] described the clinical manifestations of an isolated compression of the AIN in detail. A patient with a complete AIN palsy would present with no motor function to the FPL, FDP to the index and middle fingers, and pronator quadratus. Patients with incomplete palsies or with Martin- 

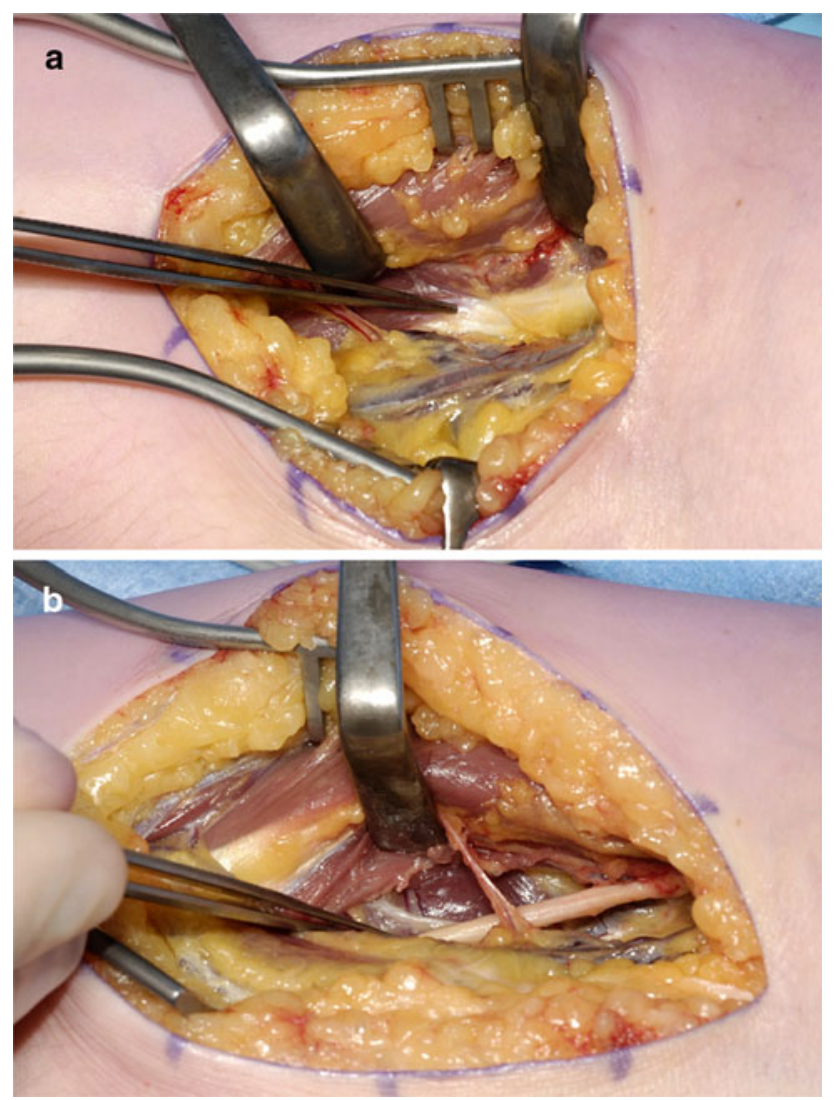

Fig. 1 Compression of left AIN due to fibrous arch of the flexor digitorum superficialis in a 35-year-old woman. a Before and $\mathbf{b}$ after decompression

Gruber anastomoses may present differently [24]. In addition, the FDP to the middle finger may not be always exclusively innervated by the median nerve. Thus, intact middle finger distal interphalangeal joint flexion does not itself exclude AIN syndrome as a potential diagnosis [7].

As in our group, most patients with AIN syndrome present with weakness or absence of FPL function. Although no sensory loss occurs, pain may be present in the forearm along the course of the nerve. This was also true in eight of our patients. The characteristic physical examination finding is a patient's inability to make an "OK" sign when asked to flex his thumb interphalangeal joint and index finger distal interphalangeal joint. Another clinical test is to ask the patient to pinch a sheet of paper between thumb and index finger using only the fingertips and then trying to pull the paper away. A patient with AIN may be unable to hold on to the sheet of paper with just his fingertips and may compensate by using a more adaptive grip in which the interphalangeal joint of the thumb and distal interphalangeal joint of the index finger remain extended [7].

Causes for AIN palsy can be divided in traumatic and non traumatic/spontaneous. Palsy of the AIN has been described in association with the neuralgic amyotrophy [10, 27], isolated neuritis [27], and entrapment neuropathy [18]. The nerve is susceptible to entrapment by soft tissue and by vascular and bony structures. According to Spinner [33], it is vulnerable to injury or compression by the following:

- a tendinous origin of the deep head of pronator teres,

- a tendinous origin of flexor digitorum superficialis to the middle finger,

- thrombosis of the ulnar collateral vessels which cross it,

- accessory muscles and tendons from flexor digitorum superficialis,

- an accessory head of FPL (Gantzer's muscle),

- an aberrant radial artery,

- a tendinous origin of palmaris longus or flexor carpi radialis brevis,

- an enlarged bicipital bursa.

Collins and Weber [6] considered entrapment to be by far the most common cause of AIN palsy. In all of our patients explored operatively, compression structures could be found. Hill et al. [13] observed it in 24 of 28 cases of incomplete palsy. Schantz and Riegels-Nielson [29] found evidence of nerve compression in nine of 15 patients.

An incomplete syndrome in which only the FLP or the FDP of the index finger is paralysed must be distinguished from flexor tendon rupture, flexor tendon adherence or adhesion, and stenosing tenosynovitis. The nerve is usually compressed by fibrous bands that most commonly originate from the deep head of the pronator teres and the brachialis fascia [13, 33].

Differential diagnosis consists of a noncompressive neuropathy, such as brachial neuritis, which may mimic the clinical manifestations of an AIN neuropathy [27]. A rupture of the FPL tendon is also possible in patients with rheumatoid arthritis. To exclude this differential diagnosis, the wrist should be passively flexed and extended to confirm that the patient has an intact tenodesis effect. A sudden onset of AIN compression symptoms associated with a viral prodrome suggests the diagnosis of such a viral neuritis (Parsonage-Turner syndrome [27]).

Important elements in the diagnosis of AIN syndrome are electrodiagnostic studies. They confirm the diagnosis and objectively assess the severity of the neuropathy. More proximal lesions can be ruled out by EMG. Also, EMG is helpful for distinguishing AIN syndrome from a flexor tendon rupture in patients with severe rheumatoid disease who have such limited wrist motion that the determination of an intact tenodesis effect is impossible. MRI is not commonly used in the diagnosis of AIN syndrome, although there is literature describing the MRI findings associated with AIN syndrome in which increased signal intensity can be seen in the AIN-innervated muscles on T2- 
weighted, fat-saturated images or short inversion time inversion recovery sequences [9, 12].

The indications of operative treatment for spontaneous AIN palsy remain controversial. Once the diagnosis of AIN syndrome is made, observation with an avoidance of aggravating activities, rest, and anti-inflammatory medication for several months has been suggested before decompression [19]. Most of the patients with AIN syndrome have an improvement without any surgical intervention [21, 24]. This was also true for our patients. There is a role for physiotherapy and this should be directed specifically towards the pattern of pain and symptoms. Soft tissue massage, stretches and exercises in order to directly mobilise the nerve tissue may be used. Spinner et al. [34] recommended exploration if no signs of clinical and electromyographical improvement occur within 6-8 weeks. Nigst and Dick [25] recommended operative treatment in patients in whom there was no improvement after the conservative treatment for 8 weeks, since surgical decompression reduces the time needed for recovery. Hill et al. [13] recommended that exploration and external neurolysis be undertaken when there is no clinical and/or electromyographical improvement by 12 weeks after onset. However, spontaneous recovery in a later course has been described by several authors [21, 30, 32]. For patients who have a spaceoccupying mass in the area, or who fail a several month course of nonsurgical treatment, surgical decompression has been recommended [21]. Randomized, controlled trials concerning the ideal duration of nonsurgical management and the timing of surgical intervention are still missing. In the absence of evidence suggesting neuritis, most authors still recommend a trial of conservative management for at least 12 weeks [32]. We also performed operative exploration in our patients after 12 weeks if no clinical and electromyographical signs of improvement were visible. During the operation, the AIN should be thoroughly decompressed from any overlying tissue and completely visualised as it travels into the distal forearm (Fig. 1). The surgical approach and extent of proximal exploration can be tailored to the surgeon's specific areas of preoperative concern. Nearly all of the median nerve's branches course off its ulnar side at this level, with the notable exception being the AIN, which branches off the radial side of the nerve. Meticulous haemostasis is essential during nerve decompression in the forearm to minimize a postoperative haematoma. Early active range of motion is allowed.

If motor function does not recover, tendon transfer will restore the function satisfactorily. The brachioradialis is a good substitute for restoring flexion of the interphalangeal joint of the thumb. The transfer of the tendon of FDP of the ring or middle finger to that of the index finger at the wrist can provide satisfactory flexion of the distal phalanx of the index finger [23]. Schantz and Riegels-Nielson [29] recommend delay in the use of tendon transfer until one year after the onset of palsy.

Conflict of interest The authors declare that they have no conflict of interest.

Open Access This article is distributed under the terms of the Creative Commons Attribution Noncommercial License which permits any noncommercial use, distribution, and reproduction in any medium, provided the original author(s) and source are credited.

\section{References}

1. Amirfeyz R, Clark D, Parsons B, Melotti R, Bhatia R, Leslie I, Bannister G (2011) Clinical tests for carpal tunnel syndrome in contemporary practice. Arch Orthop Trauma Surg 131(4):471-474

2. Arenas AJ, Artazcoz FJ, Tejero A, Arias C (2001) Anterior interosseous nerve injury associated with a monteggia fracturedislocation. Acta Orthop Belg 67:77-80

3. Bamford DJ, Stanley D (1989) Anterior interosseous nerve paralysis: an under diagnosed complication of supracondylar fracture of the humerus in children. Injury 20:294-312

4. Casey PJ, Moed BR (1997) Fractures of the forearm complicated by palsy of the anterior interosseus nerve caused by a constrictive dressing. J Bone Joint Surg Am 79:122-124

5. Chidgey LK, Szabo RM (1989) Anterior interosseus nerve palsy. In: Szabo RM (ed) Nerve compression syndromes. Slack Inc, Thorofare NJ, pp 153-162

6. Collins DN, Weber ER (1983) Anterior interosseous nerve syndrome. South Med J 76:1533-1537

7. Dang AC, Rodner CM (2009) Unusual compression neuropathies of the forearm, part II: median nerve. J Hand Surg A34: $1915-1920$

8. Duchenne de Boulogne GBA (1872) De l'électrisation localisée. vol 1. 3rd edn. J.-B. Baillière, Paris

9. Dunn AJ, Salonen DC, Anastakis DJ (2007) MR imaging findings of anterior interosseous nerve lesions. Skelet Radiol 36:1155-1162

10. England JD, Sumner AJ (1987) Neuralgic amyotrophy: an increasingly diverse entity. Muscle Nerve 10:60-68

11. Farber JS, Bryan RS (1968) The anterior interosseous nerve syndrome. J Bone Joint Surg Am 50:521-523

12. Grainger AJ, Campbell RS, Stothard J (1998) Anterior interosseous nerve syndrome: appearance at MR imaging in three cases. Radiology 208:381-384

13. Hill NA, Howard FM, Huffer BR (1985) The incomplete anterior interosseous nerve syndrome. J Hand Surg Am 10:4-16

14. Inaparthy PK, Anwar F, Botchu R, Jaehnich H, Katchburian MV (2008) Compression of the deep branch of the ulnar nerve in Guyon's canal by a ganglion: two cases. Arch Orthop Trauma Surg 128(7):641-643

15. Kelly EW, Morrey BF, O’Driscoll SW (2001) Complications of elbow arthroscopy. J Bone Joint Surg Am 83:25-34

16. Keogh P, Khan H, Cooke E, McCoy G (1997) Loss of flexor pollicis longus function after plating of the radius: report of six cases. J Hand Surg Br 22:375-376

17. Kiloh LG, Nevin S (1952) Isolated neuritis of the anterior interosseous nerve. Br Med J 1:850-851

18. Lipscomb PR, Burleson RJ (1955) Vascular and neural complications in supracondylar fractures in children. J Bone Joint Surg Am 37A:487-492 
19. Lubahn J, Cermak M (1998) Uncommon nerve compression syndromes of the upper extremity. J Am Acad Orthop Surg 6:378-386

20. Mangini U (1960) Flexor pollicis longus muscle: its morphology and clinical significance. J Bone Joint Surg 42A:467-470

21. Miller-Breslow A, Terrono A, Millender LH (1990) Nonoperative treatment of anterior interosseous nerve paralysis. J Hand Surg 15A:493-496

22. Mirovsky Y, Hendel D, Halperin N (1988) Anterior interosseus nerve palsy following closed fracture of the proximal ulna. Arch Orthop Trauma Surg 107:61-64

23. Nagano A (2003) Spontaneous anterior interosseous nerve palsy. J Bone Joint Surg Br 85:313-318

24. Nakano KK, Lundergran C, Okihiro MM (1977) Anterior interosseous nerve syndromes: diagnostic methods and alternative treatments. Arch Neurol 34:477-480

25. Nigst H, Dick W (1979) Syndromes of compression of the median nerve in the proximal forearm (pronator teres syndrome; anterior interosseous nerve syndrome). Arch Orthop Trauma Surg 93:307-312

26. O'Neill DB, Zarins B, Gelberman RH, Keating TM, Louis D (1990) Compression of the anterior interosseous nerve after use of a sling for dislocation of the acromioclavicular joint: a report of two cases. J Bone Joint Surg Am 72:1100-1102

27. Parsonage M, Turner J (1948) Neuralgic amyotrophy: the shoulder-girdle syndrome. Lancet 1:973-978

28. Puhaindran ME, Wong HP (2003) A case of anterior interosseous nerve syndrome after peripherally inserted central catheter (PICC) line insertion. Singap Med J 44:653-655
29. Schantz K, Riegels-Nielsen P (1992) The anterior interosseous nerve syndrome. J Hand Surg Br 17(5):510-512

30. Seror P (1996) Anterior interosseous nerve lesions: clinical and electrophysiological features. J Bone Joint Surg 78B:238-241

31. Sisco M, Dumanian GA (2007) Anterior interosseous nerve syndrome following shoulder arthroscopy. J Bone Joint Surg 89A:392-395

32. Sood MK, Burke FD (1997) Anterior interosseous nerve palsy: a review of 16 cases. J Hand Surg B22:64-68

33. Spinner M (1978) Injuries to the major branches of peripheral nerves of the forearm. WB Saunders, Philadelphia, pp 160-227

34. Spinner M (1970) The anterior interosseous nerve syndrome: with special attention to its variations. J Bone Joint Surg Am 52A:84-94

35. Stahl S, Freiman S, Volpin G (2000) Anterior interosseous nerve palsy associated with Galeazzi fracture. J Pediatr Orthop B 9:45-46

36. Sunderland S (1945) The innervation of the flexor digitorum profundus and lumbrical muscles. Anatom Record 93:317-321

37. Sunderland S (1945) The intraneural topography of the radial, median and ulnar nerves. Brain 68:243-299

38. Ulrich D, Ulrich F, Schroeder M, Pallua N (2009) Lipofibromatous hamartoma of the median nerve in patients with macrodactyly: diagnosis and treatment of a rare disease causing carpal tunnel syndrome. Arch Orthop Trauma Surg 129(9):1219-1224

39. Wolf MB, Kroeber MW, Reiter A, Thomas SB, Hahn P, Horch RE, Unglaub F (2010) Ulnar shortening after TFCC suture repair of Palmer type 1B lesions. Arch Orthop Trauma Surg 130(3):301-306 